\title{
A Grounded Theory of Professional Learning in an Authentic Online Professional Development Program
}

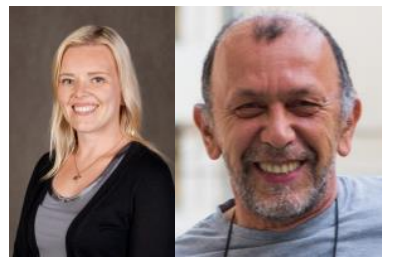

Hanna Teräs ${ }^{1}$ and Umit Kartoglu ${ }^{2}$

${ }^{1}$ University of Turku, ${ }^{2}$ World Health Organization

\begin{abstract}
Online professional development (OPD) programs have become increasingly popular. However, participating in professional development does not always lead to profound professional learning. Previous research endeavours have often focussed on measuring user acceptance or on comparing the effectiveness of OPD with a face-to-face delivery, but there is little knowledge of how the process of professional learning actually occurs in OPD. This study explores how professional learning takes place in an OPD program designed according to the principles of authentic e-learning, and how the learning design and technologies used impact on the professional learning experienced by the participants. The context of the study is an international OPD program in vaccine management developed and offered by World Health Organization. A grounded theory approach was employed to develop a theorised model of the professional learning process in an authentic online learning environment. The findings show that professional learning was facilitated in a dynamic web of interactions rather than by covering content: the learner is at the centre of the process, actively engaged in authentic tasks in collaboration with peers, while mentors and content play a supporting role. Technology facilitates and enables the web of interactions. The learning process was found to bear resemblance to the type of professional learning that occurs in authentic workplace settings, which implies that the authentic e-learning principles provide a helpful learning design framework for OPD.
\end{abstract}

Keywords: online professional development, professional learning, authentic e-learning, learning design, grounded theory, vaccine management 


\section{Introduction}

While professional development programs are increasingly often offered online, little is known of how professional learning actually takes place in online professional development (OPD) programs and what elements of the learning design and learning environment support or hinder it. This study examines how professional learning occurs in an OPD program designed and implemented according to the pedagogical model of authentic e-learning (Herrington, Reeves \& Oliver, 2010) and how the elements of the learning design and the use of technology affect the professional learning experience of the participants. The context of the study is an international OPD program in vaccine management, offered by the World Health Organization (WHO). A theoretical model of the professional learning process in an authentic online learning environment is developed using a grounded theory approach (Strauss \& Corbin, 1998). While the model can be used to inform the design, implementation, and facilitation of online professional learning programs, we believe it will potentially be helpful for other online learning contexts designed for adult learners as well.

\section{Professional Development and Professional Learning}

In this study, we define professional development (PD) as activities that are intended to engage professionals in new learning about their professional practice (Knapp, 2003), whereas professional learning (PL) is an intrinsic phenomenon. Participating in professional development activities may or may not lead to professional learning. Ruohotie (2002) describes professional learning as a continuous process that builds throughout the entire professional career or the individual. As a result, as WebsterWright (2010) summarises, "PL cannot be mandated, coerced or controlled, but can be supported, facilitated and shaped" (p. 12). This observation is a starting point for the study presented in this paper and provides a key motivation for the research task. In order to better understand the value of OPD, it is important to first understand how PL in fact occurs during the type of PD endeavour in question.

Whereas many OPD programs are based on online content delivery, examples of more pedagogically driven designs can also be found. For example, Ching and Hursh (2014) report on an OPD program that led to wide-scale innovation adoption and change in professional practice. This was seen to be a result of the learning design that built on the social constructivist belief that people construct knowledge collaboratively and learn best when creating purposeful artefacts for an authentic audience (Ching \& Hursh, 2014). The findings align with earlier research on PD and adult learning. Learner involvement, building upon experience, situated content, and problem-centered context have been suggested to be key principles of adult learning (Knowles, 1990). In line with these principles, effective professional development is believed to be social, active and practice-driven (Webster-Wright, 2010).

However, instead of the above identifiers, the advantages of OPD are often primarily associated with accessibility and flexibility regarding time and space (Dede, Ketelhut, Whitehouse, Breit, \& McCloskey, 2009); Carey, Kleiman, Russell, \& Venable, 2009). While these perceived advantages often serve as the default ground for OPD research, they tend to make assumptions of the pedagogical foundations of elearning that are seldom defined or questioned. OPD is often assumed as content delivery in the form of self-study materials and assignments, sometimes mandated by the employer. For example, Vu, Cao, $\mathrm{Vu}$, and Cepero (2014) examined factors that lead to learner success in OPD, and found self-direction, compliance to employer expectations and disciplined study routine as the most important characteristics. Kyalo and Hopkins (2013) studied the acceptance of OPD amongst medical professionals and found that while the majority appreciated the flexibility and the self-paced nature of the studies, less than third of the participants regarded the OPD program as a successful professional 
learning experience. The difficulty to remain motivated and self-directed was identified as a challenge. Moreover, OPD was found theoretical and unsuitable for practical subjects (Kyalo \& Hopkins, 2013).

Neither of these examples describes the learning design of the OPD offerings in question but seems to automatically assign OPD with content-driven self-study. Baran and Cagiltay's (2006) study examining teachers' expectations and experiences with OPD make these assumptions more explicit. Their rather discouraging observation was that the participants found the OPD experience decontextualized, theoretical, and downright boring. The only advantage was the flexibility of time and space. The participants were not eager to undertake another OPD course unless it was interactive and highly practical, and provided opportunities to problem-solve and learn from colleagues (Baran \& Cagiltay, 2006). Interactivity and collegial sharing have often been particularly difficult to achieve in OPD; Liu (2012) identifies their absence as one of the most obvious shortcomings in OPD. The issue is sometimes tackled by adding a discussion board in the online learning environment; however, these often remain underutilised. This was the case also in an OPD program evaluated by McConnell and Monroe (2012), and as a result, the design was reverted to a static website focussing on content delivery and individual assignments.

Ignoring the dimension of learning design has led to weaknesses in the evaluation of e-learning, including OPD. The effectiveness of e-learning is typically evaluated in comparison with a face-to-face delivery, reducing social interactions into quantitatively defined variables and assuming these can be controlled or randomised (Phillips, McNaught, \& Kennedy, 2012; Reeves, 2006). In such endeavours, the pedagogical and education-philosophical underpinnings of either mode are typically not defined or considered in the research design. The measurements take the form of test results or participant satisfaction surveys (e.g., Lahti, Kontio, Pitkänen, \& Välimäki, 2014; McConnell \& Monroe, 2012), or user acceptance questionnaires (e.g., Kyalo \& Hopkins, 2013; Alsofyani, Bin Aris, Eynon, \& Norazman, 2012). However, the research results remain of little applicability when "online" is presented as a pedagogical strategy in its own right, while it, in reality, is a channel through which a variety of different pedagogical designs can be employed.

Authentic professional learning. Some researchers have taken a different approach to professional development research, shifting the focus from the characteristics of the PD program to the learning process of the professionals. Vermunt and Endedijk (2011) have studied teachers' professional development and argue that most of the literature in the area is prescriptive and neglects to explore how teachers learn naturally. Similarly, Webster-Wright (2010) believes that professional development research would benefit from a better understanding of how professional learning takes place in natural work settings. She used phenomenological analysis to reveal how health care professionals keep learning in working life and developed this understanding further into a framework of "authentic professional learning" (Webster-Wright, 2010).

The present study builds on this thinking and seeks to combine the two approaches by investigating how professional learning actually takes place in an OPD program. Acknowledging that "online" is not a pedagogical design or a universal variable in its own right, we next move on to describe the learning design of the OPD program in question.

\section{Authentic e-Learning as a Design Framework for Professional Development}


We believe it is not possible to arrive in a theoretical framework of professional learning in an OPD program without considering the learning design of the program in question. Different approaches to teaching are known to lead to different learning strategies and experiences (Prosser \& Trigwell, 1999). The OPD program that forms the context of this study has been designed and implemented according to the principles of authentic e-learning (Herrington, Reeves \& Oliver, 2010). Authentic e-learning is a pedagogical framework that has originally been developed and studied in a higher education context. The goal of the framework was to apply a "model of instructional design based on the theory of situated learning to the design of multimedia learning environment for university students" (Herrington \& Oliver, 2000, p.25). The authentic e-learning framework has been widely studied in different educational contexts, including pre-service teacher education (e.g., Amiel \& Herrington, 2012; Valtonen, Kukkonen, Kontkanen, Sormunen, Dillon, \& Sointu, 2015), higher education (e.g., Bozalek et al., 2013), teacher professional development (e.g., Teräs, 2013; Parker, Maor, \& Herrington, 2013), vocational education $(\mathrm{Pu}, \mathrm{Wu}$, Chiu, \& Huang, 2016), and foreign language learning (Ozverir, Herrington, \& Osam, 2016). However, applications of authentic e-learning in industry and organisations are still scarce. Most examples involve linking students with industry through projects, placements, or authentic practices (e.g., Collis, Foth, \& Schroeter, 2009; Pu et al., 2016). This study makes a contribution to the research of authentic e-learning by applying the model in a professional development context and presenting a theoretical model of how exactly professional learning might take place in an authentic e-learning based program.

The authentic e-learning framework provides learning design guidelines for translating the pedagogical ideas of situated learning (Lave \& Wenger, 1991) into practice in online education. Being based on the notion that learning occurs best when it is embedded in context, activity, and culture, situated learning is a natural match for professional development and training purposes (e.g., Machles, 2003). One of the claims for authentic learning is that it is able to bridge the gap between formal education and the expectations of society and working life better than traditional methods based on the delivery of abstract and decontextualized content (Herrington et al., 2010). It moves away from traditional university course activities, such as lectures, readings, and examinations to an approach where the focus of the course is in an authentic project. Such an approach is well suited for professional development perhaps even more easily than in a higher education context where the constraints of traditional academic practices are often hindering the development of authentic e-learning courses (Herrington et al., 2010).

The role of technology in an authentic e-learning environment differs significantly from the commonly seen practice of using technology as an information delivery channel, where content is delivered to students by technology, students use technology to complete assignments to indicate that they have processed the content, and the teacher uses technology to assess the adequacy of the student's response, or the response is assessed automatically. Herrington et al. (2010) refer to this as learning from technology. By contrast, learning with technology uses technology as cognitive tools that learners use for constructing knowledge, solving problems, collaborating, and articulating their knowledge to others. The latter is assumed in authentic e-learning. 
The authentic e-learning framework consists of nine elements that align closely with success factors identified in earlier professional development research, as well as with central adult learning theories. These elements are described in the following.

1) Authentic context which is not created merely by providing real world examples, but Herrington et al. (2010) define it as "need(ing) to be all-embracing, to provide the purpose and motivation for learning, and to provide a sustained and complex learning environment that can be explored at length" (p.19). An authentic context must reflect the way the knowledge will be used in real life; therefore, it must also preserve the complexity of the real life setting.

2) Authentic tasks are the core of an authentic learning design. In addition to having strong real-life relevance, they are as ill-defined and complex as real world problems tend to be. Authentic tasks are long-term efforts and result in a polished product. The importance of such tasks in professional development has been known for a long time: Ling and MacKenzie (2001) found that successful professional development is a long-term process that offers opportunities for practical implementation. The same has later been confirmed in other studies (Lawless \& Pellegrino, 2007; Garcia \& Roblin, 2008). These observations support Knowles' (1990) notion that adult learners require situation-relevant content and prefer to work within a problemcentered context.

3) Access to expert performances and the modeling of processes is an idea that originates from apprenticeship learning. In the context of professional development this means that the learners have the opportunity to observe how experts solve problems as well as learn with and from their colleagues. The idea of apprenticeship is also found behind Lave and Wenger's (1991) influential and widely studied ideas of situated learning, legitimate peripheral participation and communities of practice.

4) Promoting multiple roles and perspectives ensures that learners are exposed to controversies, debates, and discussion, as well as to various sources of information rather than a single textbook or teacher's lecture notes. The benefits of learning environments that promote dialogue and collegial sharing have been identified in different OPD studies worldwide. For example, Garcia and Roblin (2008) and Löfström and Nevgi (2007) have found that sharing of viewpoints and experiences enhances the work performance of professionals.

5) Collaborative construction of knowledge is a key characteristic of authentic learning and a widely stated success factor of professional development. Collegial sharing (Ling \& MacKenzie, 2001), interdisciplinary teamwork (Garcia \& Roblin, 2008), as well as interaction and collaboration between participants (Liu, 2012) have all been recognized as key ingredients in effective professional development.

6) Reflection in authentic learning can be promoted by requiring participants to make decisions regarding completing tasks, by presenting materials in a non-linear fashion that allows free navigation and acting upon reflection, and by offering opportunities to compare one's thoughts to the ideas of other learners, experts, and mentors. The role of reflection in adult learning is long recognized (Schön, 1983) and it has also been identified as a feature of quality professional learning (Lawless \& Pellegrino, 2007; Garcia \& Roblin, 2003). 
7) Articulation is encouraged when the tasks require the participants to discuss their growing understanding, negotiate meaning, and publicly present and defend arguments. In accordance with this principle, Garcia and Roblin (2007) found that promoting articulation through weblogs in OPD enhanced reflection, the development of metacognitive abilities, creativity, and interaction between colleagues.

8) An authentic e-learning course "provides for coaching at critical times, and scaffolding of support, where the teacher provides the skills, strategies, and links that the students are unable to provide to complete the task" (Herrington et al., 2010, p. 35). Similarly, Ling and MacKenzie (2001) maintain that successful professional learning is well supported.

9) Authentic assessment is not separated from the learning process, but is seamlessly integrated in the activities. Moreover, authentic assessment requires that learners be provided with the opportunity to be effective performers with the skills and knowledge they have acquired.

\section{Research Context}

The participants of the study consist of experts in immunisation, vaccine management, and pharmaceuticals that completed an OPD course in Vaccine Vial Monitor (VVM) based vaccine management offered by the WHO and EPELA (Extensio et Progressio, Authentic e-Learning) (http://epela.net/epela_web/evvm.html). The participants of the OPD program consisted of both men and women from different organisations all around the world, mostly from different African and Asian countries. The OPD program took place fully online and the participants never met each other or the mentors physically. VVM is a label containing a heat-sensitive material, which is placed on a vaccine vial to register cumulative heat exposure over time. The VVM label indicates whether the administered vaccines have been damaged by heat or not, consequently helping to reduce vaccine wastage, identify cold chain problems and manage vaccine stocks. The eVVM OPD course aims to develop sound vaccine management skills using VVMs. Instead of delivering the course content in the form of readings and lectures, the OPD program invites participants to interact and learn within an authentic online learning environment that simulates a vaccine cold chain. The course spans over nine weeks, during which the participants travel virtually from one level to another in the supply chain, assuming the relevant professional roles in situations ranging from international arrival of the vaccines to storage and a plan of action to adopt VVM policies for national use. On each level, participants engage in authentic tasks, solving similar problems as they would in a real-world situation and producing outcomes that can actually be used in the field for authentic working purposes. They work in teams, reflect on their learning both individually and collaboratively, and receive continuous feedback from mentors and peers. As a result, the participants develop and apply advanced decision-making and planning skills. The course does introduce short expert videos and reference materials about the subject matter, but the most important learning opportunities are enabled via authentic tasks. Self, peer, and mentor review are important aspects of assessment. Following five weeks of virtual visits, participants are introduced to a real client so that together with their peers as consultants they analyse a real world cold chain challenge and make recommendations to the client. Figure 1 illustrates the course flow and the activities of the participants and mentors during the course. 


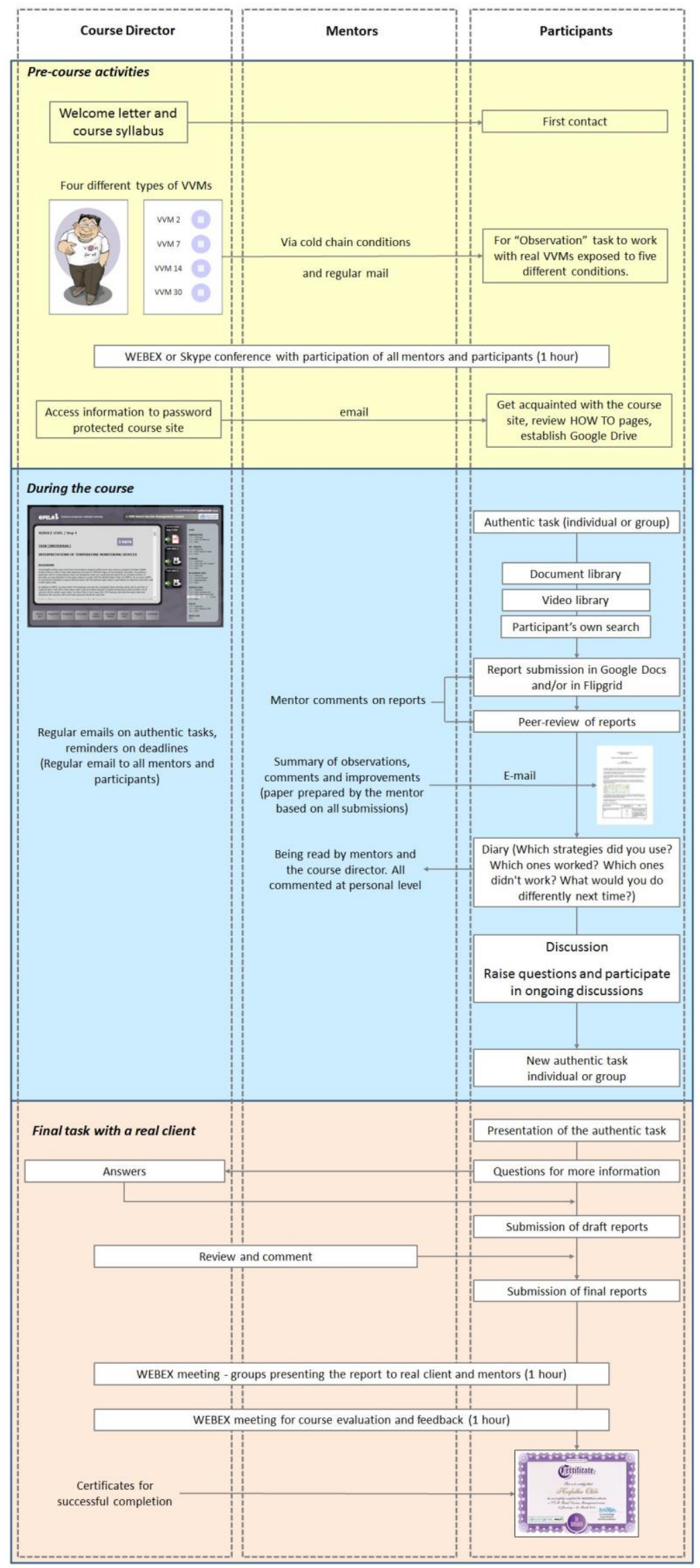

Figure 1. The flow of the eVVM online professional development course. 
The process illustrated in the figure above takes place in the online learning environment of the course, utilising a variety of technologies for different purposes. The learning environment has been designed to integrate the authentic learning principles. In addition to the online technologies, the participants receive a set of real physical VVM cards for observation. Table 1 illustrates how the nine principles of authentic learning were used in the course and how the technologies supported this.

Table 1

Authentic Learning Principles and Technologies in the VVM OPD Course

\begin{tabular}{|c|c|c|}
\hline Authentic learning principle & How the principle was used & Technologies \\
\hline Authentic context. & $\begin{array}{l}\text { The vaccine supply chain is } \\
\text { represented through virtual visits } \\
\text { implemented with } 360^{\circ} \text { videos and } \\
\text { authentic documentation. } \\
\text { Authentic practices and } \\
\text { approaches are employed in all } \\
\text { learning tasks. }\end{array}$ & $\begin{array}{l}\text { EPELA environment, } \\
\text { which integrates virtual } \\
\text { steps of the vaccine } \\
\text { supply chain with the } \\
\text { authentic tasks, resources } \\
\text { and tools. } \\
\text { VVM cards that the } \\
\text { participants observe and } \\
\text { experiment with. }\end{array}$ \\
\hline Authentic tasks. & $\begin{array}{l}\text { All tasks are designed based on } \\
\text { actual real life problems that are } \\
\text { complex and ambiguous. The tasks } \\
\text { are completed over an extended } \\
\text { period of time. All tasks are } \\
\text { designed based on real-world } \\
\text { problems notified to WHO. }\end{array}$ & $\begin{array}{l}\text { Google Drive provides } \\
\text { participants access to } \\
\text { shared folders for } \\
\text { submission of task } \\
\text { reports and peer review. } \\
\text { WebEx is used as a } \\
\text { conference platform for } \\
\text { the final task for groups } \\
\text { to present their work to } \\
\text { the real client. } \\
\text { VVM cards. } \\
\text { - Skype, WhatsApp and } \\
\text { Facebook used for } \\
\text { communication when } \\
\text { working on these tasks. }\end{array}$ \\
\hline $\begin{array}{l}\text { Access to expert performances } \\
\text { and modelling of processes. }\end{array}$ & $\begin{array}{l}\text { Expert videos, access to mentors, } \\
\text { sharing of participant expertise } \\
\text { through collaborative tasks. }\end{array}$ & $\begin{array}{l}\text { Video and document } \\
\text { libraries provide } \\
\text { authentic resources such } \\
\text { as expert videos and } \\
\text { scientific papers. } \\
\end{array}$ \\
\hline Multiple perspectives. & $\begin{array}{l}\text { Versatile materials (video \& } \\
\text { document library) presented in a } \\
\text { non-linear fashion. }\end{array}$ & $\begin{array}{ll}\text { - } & \text { Video and document } \\
\text { libraries. } \\
\text { Discussion forums for } \\
\text { sharing perspectives, } \\
\text { asking questions, and } \\
\text { discussing experiences in } \\
\text { different contexts. }\end{array}$ \\
\hline $\begin{array}{l}\text { Collaborative construction of } \\
\text { knowledge. }\end{array}$ & $\begin{array}{l}\text { Participants access and comment } \\
\text { on each other's work. Individuals } \\
\text { and groups create reports and } \\
\text { recommendations as well as mind } \\
\text { maps, flow charts and decision } \\
\text { trees for processes - these } \\
\text { documents are now in use in the } \\
\text { field. }\end{array}$ & $\begin{array}{l}\text { Several tools are used for this } \\
\text { purpose throughout the course: } \\
\text { - Skype } \\
\text { - } \quad \text { Discussion forums } \\
\text { - } \quad \text { Google Drive }\end{array}$ \\
\hline Reflection. & $\begin{array}{l}\text { Participants keep a diary to reflect } \\
\text { on authentic tasks, their learning } \\
\text { and approaches to solve problems. } \\
\text { Diary entries are made following } \\
\text { completion of the tasks, peer } \\
\text { review and mentor comments, }\end{array}$ & $\begin{array}{l}\text { - } \quad \text { Online diaries. } \\
\text { Scavenger hunt blog } \\
\text { where participants are } \\
\text { given a list of situations to } \\
\text { observe and photograph } \\
\text { in their own working } \\
\text { contexts and post them in }\end{array}$ \\
\hline
\end{tabular}




\begin{tabular}{|c|c|c|}
\hline & $\begin{array}{l}\text { enabling critical reflection on } \\
\text { action. }\end{array}$ & $\begin{array}{l}\text { the blog along with a } \\
\text { story of each situation. }\end{array}$ \\
\hline Articulation. & $\begin{array}{l}\text { Diaries, Flipgrid videos and course } \\
\text { director's one-on-one interactions } \\
\text { with participants about their diary } \\
\text { entries provide articulation } \\
\text { opportunities. }\end{array}$ & $\begin{array}{cl}\text { Several tools support articulation: } \\
\text { - } & \text { Diaries } \\
\text { - } & \text { Flipgrid } \\
\text { - } & \text { Discussion forums } \\
\text { - } & \text { WebEx }\end{array}$ \\
\hline Scaffolding and coaching. & $\begin{array}{l}\text { Mentors are readily reachable via } \\
\text { Skype, email and other means. In } \\
\text { each authentic task, mentors } \\
\text { provide prompt constructive } \\
\text { feedback. }\end{array}$ & $\begin{array}{ll}\text { - } & \text { Discussion forums. } \\
\text { - Skype for both group and } \\
\text { individual mentoring. } \\
\text { - } \quad \text { Email. } \\
\text { Google Drive for feedback } \\
\text { and comments on } \\
\text { participants' work. }\end{array}$ \\
\hline Authentic assessment. & $\begin{array}{l}\text { Authentic assessment is embedded } \\
\text { within the authentic tasks. } \\
\text { Products resulting from these tasks } \\
\text { include reports, presentations, } \\
\text { peer reviews and learning diaries. } \\
\text { These are used to assess the } \\
\text { learning of each individual. }\end{array}$ & $\begin{array}{ll}- & \text { Diaries. } \\
\text { - } & \text { Discussion forums. } \\
\text { - } & \text { Google Drive. } \\
\text { - } & \text { WebEx. }\end{array}$ \\
\hline
\end{tabular}

\section{Methodology}

A grounded theory approach was employed for the research task. Grounded theory seeks to determine how the actors respond to different conditions and the consequences of their actions (Corbin \& Strauss, 1990). The purpose of grounded theory is thus to develop a theoretical explanation for a process or an action through the process of constant comparison (Strauss \& Corbin, 1998). This theoretical explanation is grounded in and generated from the qualitative data produced by the participants. As Strauss and Corbin (1998) emphasise, a theory goes beyond a set of findings in that it offers an explanation about phenomena. In the case of the present study, the aim was to explain the occurrence of professional learning, grounding that explanation on the actual experience of the participants to the eVVM course.

\section{Collection and Analysis of Data}

The data was collected through semi-structured interviews with seven participants who completed the eVVM course, as well as through observations in the online learning environment. The interviews were conducted via Skype and they were recorded and transcribed. The length of the interviews varied from 30 minutes to one hour. The interview questions invited the interviewees to reflect on and describe their learning experience and discuss the impact the course had on their professional growth.

The analysis followed the coding procedures described by Strauss and Corbin (1998). In grounded theory, data collection and analysis are interrelated processes (Corbin \& Strauss, 1990): the analysis starts with the first bits of data and directs the next steps in data collection. In this study, the first bits of data were collected through observations in the online learning environment. These observations guided the interviews and informed the formation of interview questions. As the interviews were being completed, they were first listened to again and transcribed, after which the transcripts were read through repeatedly. This initial process allowed the researcher to immerse in the data, become more familiar with it, and identify initial points of interest. This stage was followed by the process of open coding, which involves identifying concepts in the data. Conceptual labels are given to incidents, events, and happenings, in order to be able to analyse them as potential indicators of phenomena. Concepts are 
thus the basic units of grounded theory analysis (Corbin \& Strauss, 1990). An effort was made to generate codes that would capture what essentially was going on with regard to professional learning. At the same time, memoing was used to record questions, interpretations, and thoughts that rose from the data, to facilitate a detailed, in-depth analysis that would result in an adequate code. The process of memoing is an integral part of grounded theory as it provides a system for the researcher to keep track of all categories, properties, questions, and hypotheses that result from the analysis process (Corbin \& Strauss, 1990).

The concepts identified were labelled in the transcripts and organised into categories with the help of concept mapping and constant comparison of data, codes, and emerging categories. Corbin and Strauss (1990) refer to categories as the "cornerstones of a developing theory" (p. 7) as they allow for the theory to be integrated. As a result of the process, the coded concepts represent abstractions derived from the responses of many participants. Table 2 illustrates an example of how codes were organised into categories. For example, some of the interviewees talked about how they had enjoyed the group work activities, whereas some others mentioned how they had been able to learn from their colleagues who knew more than they did about a certain issue. Although these concepts are not exactly the same, they both describe experiences that may be categorised as "appreciating collaborative learning."

Table 2

Example of Codes and Categories

\begin{tabular}{|l|l|}
\hline Open codes & Categories \\
\cline { 1 - 1 } Enjoying group work & \multirow{2}{*}{ Appreciating collaborative learning } \\
\cline { 1 - 2 } Appreciating small, rotating groups & \\
\cline { 1 - 1 } Learning from a more knowledgeable & \multirow{2}{*}{ Challenges with collaboration } \\
\cline { 1 - 1 } Group member not responding to emails & \multirow{2}{*}{ Collaborating beyond course requirements } \\
\hline Juggling between commitments & \\
\cline { 1 - 1 } Testing scenarios with peers & \\
\cline { 1 - 1 } Comparing professional contexts &
\end{tabular}


After the process of open coding, the next stage of axial coding involves relating categories to their subcategories and testing their relationships against data (Corbin \& Strauss, 1990). Through axial coding, the number of codes is reduced and connections and relationships among them are uncovered (Strauss \& Corbin, 1998; Moghaddam, 2006). For example, the subcategories of appreciating collaborative learning, challenges with collaboration, and collaborating beyond course requirements were grouped together under the axial code "experiencing collaborative learning." The final stage of the analysis is the process of selective coding. In this stage, a central category is chosen and other categories are related to it (Strauss \& Corbin, 1998, Moghaddam, 2006). A central category must be one that all other major categories relate to, either as actions, conditions, or consequences. It must also appear in the data so frequently that, in almost all cases, there will be indicators pointing to that concept. (Corbin \& Strauss, 1990). The central category that emerged from the data in this process was "professional learning as interactions." During the process of selective coding, the categories were integrated and developed into a theoretical scheme (Strauss \& Corbin, 1998). This was facilitated by reviewing and sorting memos, diagramming, and revisiting all the interviews to compare the scheme against the raw data. A theorised framework was then formed by connecting the dots and identifying the factors that enable or hinder these interactions.

\section{Research Findings}

As Corbin and Strauss (1990) point out, the interrelatedness of data collection and analysis in the grounded theory process allows for the research process to capture all relevant aspects of a topic as soon as they are encountered. In this study, one of the first points of interest to catch the attention during the early stages of the research process was that all participants were already experienced in e-learning. Some had completed a considerable number of OPD courses. However, they emphasised that the eVVM course was different from their previous experiences because of the authentic learning approach.

This was definitely very problem based learning. A lot of MOOCs have been done very well, but there's still a lot of aspects that deal with a lot more theoretical content, rather than: "you are now a manager of a health unit and you have to deal with these types of problems." There is a lot of grey area in how you deal with it and how you make decisions. So, that was the difference. It was very hands on (Participant 5).

Secondly, most interviewees described very tangible learning outcomes that impacted directly on their practice, rather than accumulating merely theoretical knowledge. One of the participants reported: "Now that I've done it physically, I can explain it," referring to a recent fieldwork situation where he had been able to apply his new skills with the VVM observation. Other examples included the ability to use some of the authentic products developed during the course in the field. A third early observation was that no one emphasised the "usual" benefits of e-learning associated with flexibility with regard to time and space. Instead, they highlighted the high degree of realism, relevance, and practicality of the course.

The different thing, when I'm comparing the eVVM with the rest of the eLearning courses....The realistic task! When I was doing my eVVM course, we had some complex collaborative tasks with colleagues from different countries. So we're dealing with, you know, actual tasks. (Participant 1) 
The first provisional concepts in the study were thus "difference from other OPD programs," "realistic task," and "impact on professional practice". As outlined by Corbin and Strauss (1990), provisional concepts are validated and later included in the theory if they are repeatedly present or significantly absent in the data. The repeated mentions of the benefits of the authentic tasks and, on the other hand, the lack of discussion around the "usual" benefits of e-learning were both considered significant.

Other sub-categories that emerged from the data were organised through the process of axial coding into eight categories: the learner, authentic tasks, authentic learning resources, collaboration with colleagues, scheduling, mentoring, technology, and impact on professional practice. Through further refining and selective coding, "learning as a web of interactions" emerged as a central category. The eight categories all relate to the central category, either as causal conditions, contextual conditions, consequences, or strategies, explained in further detail in the following section.

\section{Learning as a Web of Interactions}

A model of professional learning as a dynamic web of interactions, facilitated by technology, started to form during analysis (see Figure 2). At the centre of the web of interactions is the learner who engages in authentic learning tasks in collaboration with her or his peers, supported by the mentors, and making use of authentic learning resources. Technology facilitates these interactions as a means of communication, as tools for collaboratively preparing the authentic tasks and sharing the products, and as a way of accessing the supporting learning resources. All interactions are reciprocal: each person involved brings in a unique contribution that has an impact on another person's learning process. In this sense, the process cannot be fully predicted or replicated.

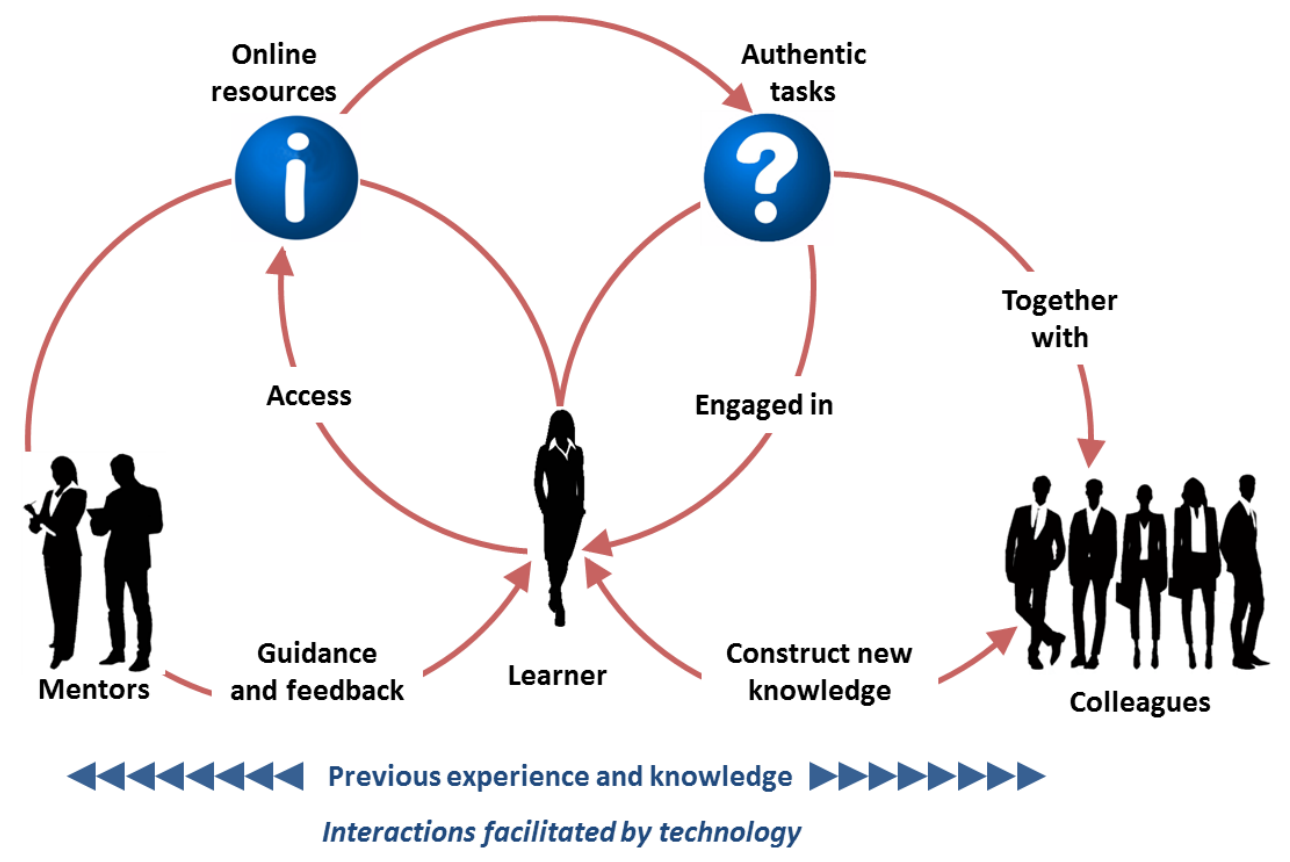

Figure 2. A framework of professional learning in authentic learning based OPD. 
The learning interactions illustrated in the framework do not exist in a vacuum, nor do they have their starting and ending points within the scope of the OPD program, as illustrated in the following interview excerpt: "(T)he course is over but there's a couple of us that are still communicating and digesting...we take a scenario and we kind of change it a little bit, and add our own experiences we used to deal with" (Participant 5).

The interactions were influenced by different forms of prior professional learning, such as existing professional networks, as well as attendance to other professional development programs either prior to or concurrently with the eVVM program. Moreover, the interactions were spontaneously deepened beyond the requirements of the program and continued afterwards in the form of ongoing discussion, strengthened networks, and collegial bonding. It is therefore noted that the learning interactions cannot be fully designed and managed, nor can they always be expected to occur in a similar manner. This is not to say that they cannot be supported and facilitated. Each of the elements in the framework can contain qualities that either promote or hinder the interaction and thus learning. Evidence of both types of qualities was found in the data, as explained in the following section.

\section{Qualities that Promote the Learning Interactions}

The first of the eight categories related to the central category is the learner. In the web of interactions, the learner is the active subject and in the centre of the interaction. The most important qualities that either promote or hinder the learning interactions are therefore attached to the learner. The crucial importance of commitment to studies was emphasised in the data. Without commitment from the learner's side, meaningful learning interactions cannot take place. Commitment should not be regarded an inherent quality that the learner either has or has not, rather, it is something that can be supported and encouraged, as well as smothered and discouraged. Striving for an authentic learning experience is a key measure in encouraging commitment: "(A)ll of the activities were very useful because they were based on a realistic task...it can increase personal commitment in terms of continuing with the course" (Participant 1). This includes ensuring the practical relevance of the professional development program for the target group, as well as employing an appropriate authentic learning design.

The categories of authentic tasks, authentic learning resources, collaboration with colleagues, scheduling, and mentoring all relate to the central category as causal or contextual conditions. Table 3 illustrates the qualities of these categories that promoted or posed challenges to the learning interactions.

Table 3

Elements That Promote/Impede Learning Interactions

\begin{tabular}{|l|ll|l|}
\hline Category & Promoting qualities & Challenges \\
\hline Authentic tasks & $\bullet$ & Realism and practical nature & Time constraints \\
& $\bullet$ & Complexity & \\
& $\bullet$ & Collaboration & \\
& $\bullet$ & Intellectual challenge & \\
& $\bullet$ & Meaningful use of digital technology & \\
\hline Colleagues & $\bullet$ & Global network & - Unresponsive group member \\
& $\bullet$ & Shared interest & Drop-out during group work \\
& & & Work across time-zones \\
& & Unavailability of colleagues \\
\hline
\end{tabular}




\begin{tabular}{|c|c|c|}
\hline & $\begin{array}{ll}\text { - } & \text { Ability to share experiences and test } \\
& \text { scenarios } \\
\text { - } & \text { Ability to see each other's work } \\
\text { - } & \text { Feedback and comments }\end{array}$ & \\
\hline Learning resources & $\begin{array}{ll}\text { - } & \text { Authentic resources instead of } \\
\text { - } & \text { textbook } \\
\text { Just-in-time instead of predefined } \\
\text { readings } \\
\text { - } \quad \text { Clear and systematic presentation } \\
\text { - } \quad \text { Evailability for future reference } \\
\end{array}$ & $\begin{array}{ll}\text { - } & \text { Bandwidth requirements } \\
\text { - } & \text { Length of documentation } \\
\text { - } & \text { Not downloadable }\end{array}$ \\
\hline Scheduling & $\begin{array}{ll}\text { - } & \text { Tight schedules facilitate } \\
\text { concentration } \\
\text { - } \\
\text { - } \quad \text { Increased commitment } \\
\text { - } \quad \text { Encourage to do one's best } \\
\end{array}$ & 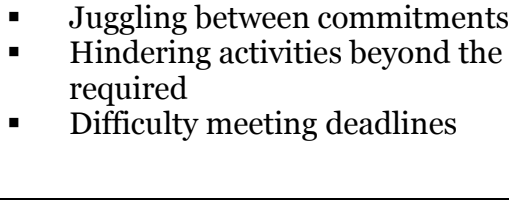 \\
\hline Mentors & $\begin{array}{ll}\text { - } & \text { Availability } \\
\text { - } & \text { Timely feedback } \\
\text { - } & \text { Clarity of instructions } \\
\text { - } & \text { Good course management }\end{array}$ & \\
\hline
\end{tabular}


Authentic tasks and collaborative learning were new to most participants, although all were experienced in OPD. This suggests that the principles of authentic learning are not yet very widely employed in OPD. Despite the newness, these features were appreciated by the participants. When describing the authentic tasks, some emphasised that the tasks were not only relevant and realistic, but they were "real practice." These statements challenge the traditional way of perceiving e-learning as better suited for theoretical learning: "Instead of just somebody presenting information, you could see how it would work in the field. So it gave us a better depth of understanding and practical application" (Participant $5)$.

My best learning activity was the case study...because in that one I had to assume I'm the one doing the investigation on ground... how the VVM changed, I didn't have that experience. But now I think I know how I would do that investigation. It was realistic. (Participant 3)

Some of the participants would have appreciated more time to complete the tasks, whereas others found that the deadlines actually increased focus and commitment. Almost all pointed out that they had put in their best effort, which indicates a deep level of engagement with the tasks: "I and my partner we actually did a lot of work on the case study and the presentation as well. We put in our very best" (Participant 2).

All participants appreciated the collaboration with colleagues. Each participant brought a unique set of experiences to the course environment. The participants tapped into this resource and at times, discussions evolved beyond course expectations as participants shared experiences, compared professional contexts, and tested scenarios. Some continued to work together after completing the course, establishing lasting professional relationships. Learning from and with others was repeatedly emphasised as a beneficial and meaningful way of professional learning.

On the other hand, the busy schedules of the participants made it difficult to stay on track with the group tasks and there were cases where a group member was unresponsive or did not contribute to the task. In such cases, the role of skilful facilitation and good course management was emphasised. All participants were juggling between commitments, and some found it difficult to meet deadlines. On the other hand, others found that the busy schedule increased their commitment to the studies and encouraged them to do their best.

Based on the findings, learning resources that promote interaction are authentic, innovative, and relevant. They are based on real environments and scenarios that the participants can identify and relate to. Other important qualities include easiness of navigation, clear presentation, as well as accessibility (adequate length, format, and alternatives for materials that require ample bandwidth). The most important qualities of mentoring included availability of the mentors, active communication, clear instructions, good course management (e.g., dealing with group issues), as well as constructive feedback. 


\section{The Role of Technology}

The category of technology relates to the central category as strategy: technology served as an enabler of the different learning interactions. While the course introduced a very wide range of technologies, no major technology-related challenges emerged from the data. The participants mentioned technology mostly when referring to learning experiences that were enabled by technology, such as organising vaccine vials in a refrigerator in a simulation, participating in a stimulating discussion, or giving presentations in a web-conference. Technology was also mentioned when describing communication with peers and mentors. The role of technology as a vehicle for distributing information gained minor attention compared to the roles of enabling active learning experiences and communication.

\section{Experienced Impact of the Program}

The last one of the categories, impact on professional practice, relates to the central category as a consequence. The impact of the eVVM course on professional learning described by the participants fell into three sub-categories: impact on professional practice, impact on self, and impact on the wider community. The impact on professional practice included improved decision-making in vaccine stock management, ability to use the VVM to determine whether a vaccine can be used, as well as developing a robust mental model on how to manage vaccines with VVM. The authentic task played a central role in achieving this impact: "With the observation of the VVM that we did, that actually gave me a kind of visual understanding of the principles in VVM management... now that I've done it physically, I can explain it" (Participant 2). The impact on self could be seen as increased self-confidence and trust in one's ability to perform new tasks, expanded professional network, as well as strengthened professional identity.

The impact on the wider community that followed the professional learning was significant: reduced wastage, improved outreach services, increased accessibility, and coverage of immunization programs, increased storage life of vaccines and reduced damage during transportation: "So you can increase the services, you can increase the accessibility, and even the coverage. So you reach more children" (Participant 1).

\section{Discussion and Implications}

This study has examined how professional learning occurs in an authentic e-learning based OPD program. There are three key features in the learning interactions model that may inform OPD development and implementation. Firstly, online professional learning can be practice-oriented and result in changes in the field. The impact in the case presented in this paper was felt on the three levels of professional practice, professional identity, and impact on wider community. Secondly, OPD that has such an impact goes beyond content acquisition and information delivery and provides the participants with opportunities to engage in authentic professional tasks that are similar to what they would perform in the actual field and collaborate with colleagues in solving problems. Thirdly, such a model is heavily learner centred and requires active commitment. Therefore, a robust authentic learning design, meaningful use of technology as cognitive tools, as well as skilful facilitation play a crucial role. Interestingly, the way professional learning took place in the interactions has parallels with the authentic professional learning framework presented by Webster-Wright (2010), implying that 
professional learning occurred in a way that resembles the way professionals naturally learn at work. Based on this observation, the authentic e-learning model (Herrington et al., 2010) appears to be a promising learning design framework for OPD.

The learning interactions were not only directly related to the course content and learning tasks, but spontaneously extended beyond course requirements as the participants' discussions moved away from the course platforms towards testing hypotheses, comparing situations in the field, and questioning and suggesting solutions to problems, and continued to do so after the course had ended. This phenomenon supports the observation that the professional learning that took place resembled the way professionals learn in authentic work situations, as opposed to simple information delivery. This is, in fact, not dissimilar to the early stages of a community of practice (Wenger, McDermott, \& Snyder, 2002). Like professional learning, communities of practice cannot be forced but they form voluntarily when a group of people find value in interacting. The following description of communities of practice aligns with what some participants experienced:

(T)hey spend time together, they typically share information, insight, and advice. They help each other solve problems. They discuss their situations, their aspirations, and their needs. They ponder common issues, explore ideas, and act as sounding boards. ...They also develop personal relationships and established ways of interacting (Wenger et al., 2002, pp.4-5).

This is not to say that authentic learning is a silver bullet that will automatically result in the formation of a community of practice. As Wenger et al. (2002) point out; communities of practice form on their own as a natural part of organisational life, they cannot be forced with the help of an intentional learning design. They cannot be managed, controlled, and directed. Attempting to force the participants of a PD program to form a community of practice is therefore doomed to be unsuccessful. However, communities of practice can be cultivated by creating an environment where they can thrive: making time and resources available, valuing their learning, and giving them a voice in decisions (Wenger et al., 2002). It does seem that the authentic e-learning design promotes real-life relevance, complexity, and collaboration that are often absent in formal OPD but may be helpful in creating an environment where the unforced creation of a community of practice is possible.

Engagement is another identifier of authentic professional learning. According to Webster-Wright (2010), active engagement in practice is not merely desirable, but essential to the experience of learning as professional. Authentic tasks provide a feasible way of integrating this dimension in OPD. In Webster-Wright's model, engagement requires for the professional to care about the situation. It is therefore crucial that the OPD program is directly relevant to the participants' context and they can see how it impacts on practice. Engagement also involves dealing with uncertainty and working out solutions, often with help from colleagues. In fact, "uncertainty is an important feature of learning" (Webster-Wright, 2010, p. 122). This aligns with authentic e-learning which assumes that the complexity of the real world is retained in the learning environment and reflected in the learning tasks. In this study, these features were seen to foster commitment to learning, which is one of the most important factors that may either support or hinder learning interactions. These findings resonate with earlier research regarding the role of motivation and self-regulation as crucial factors in initiating and fostering commitment. According to Corno and Kanfer (1993), the processes involved in motivation affect decision-making and commitment with respect to an individual's goals. However, as Ruohotie (2002) points out, motivation alone is not sufficient as even a highly motivated person may find it 
challenging to follow through her or his intentions. Therefore, conative skills are needed to maintain commitment (Pintrich, 1999). Ruohotie (2002) suggests that these skills can be fostered by learning designs that promote learner autonomy, collaborative learning, and meaningful learning tasks. In the light of the present study, authentic e-learning seems to provide a useful framework for such a design. In designing OPD, it is important to keep in mind that the program must be intrinsically motivating for the practitioners and serve their personal professional learning needs. Merely compliance-driven professional development is unlikely to promote a sense of ownership and commitment in the participants.

The authentic professional learning model emphasises the temporal and social interconnectedness of professional learning (Webster-Wright, 2010). Temporally, learning is not isolated to a single transition situation but is continuous, dynamic, and iterative. This aspect is also an important part of the learning interactions framework suggested in this study: learning interactions do not begin at the beginning of a course, nor do they end when the course does. Socially, learning occurs through dynamic interactions with others. In collaborative learning situations, one learns with others (collaborative problem solving, working together), from others (multiple perspectives, knowledgeable colleagues), as well as about others (empathy, appreciating different viewpoints). Evidence of all three was found in this study.

As Webster-Wright (2010) points out, professional learning is open-ended and requires openness of attitude. This is evident also in the learning interactions model: professional learning does not have a beginning and an end, and it can only occur when the professional cares enough to commit to the learning interactions. Therefore, a model of how professional learning occurs in an authentic e-learning based OPD program will inevitably remain incomplete. The course ends but learning continues, and what each individual takes home will vary. In that sense, attempts to determine very detailed "learning outcomes" may be futile. Rather, authentic learning based OPD provides opportunities to learn professionally through authentic tasks, collaborating with others, reflecting and articulating, accessing latest knowledge and expertise, scaffolded, and coached by capable mentors. These processes facilitate the interactions that spark professional learning.

\section{Conclusion}

In this study a grounded theory approach was used to examine how professional learning takes place in an OPD program designed and implemented according to the principles of authentic e-learning, as well as to understand the impact of the authentic learning design on the professional learning experience of the participants. The context of the study was an OPD program in vaccine management offered by the WHO. A key outcome of the study is a theoretical model of learning interactions that may be beneficial for professional development providers, online learning designers, online educators, and online learners. Understanding the mechanisms of online professional learning and the implications for OPD will also provide insight for decision-making and policy development in the relevant sectors.

In the theoretical model that was developed in this study, online professional learning occurs through interactions rather than by consuming content. Enabled by technology, the learner, colleagues, mentors and authentic curriculum all interact with each other in layers, each layer bringing in added value and promoting learning. Curriculum therefore becomes enriched with knowledge from the participants and mentors. It is not a ready-made package that can be delivered and consumed, but rather a dynamic 
series of interactions that lead to collaborative construction of new knowledge. The role of technology is to create an interactive learning environment, which enables and facilitates these interactions. The authentic e-learning model provides a helpful pedagogical framework for creating such a learning environment.

Parallels with the authentic professional learning model could be detected in the theoretical model of learning interactions. There was evidence of professional learning taking place with impact on practice, self, and wider community. These findings imply that authentic e-learning based OPD may enable learning that resembles the way professionals learn naturally in the workplace.

Finally, it can be suggested that learning design is a key component in OPD research as it contextualises the findings, improving their applicability, and comparability. It is crucial to realise that e-learning in itself is not a pedagogical dimension, rather, it is just a delivery mode. Further research into OPD learning design would therefore be in place. Holistic approaches, such as design-based research or a phenomenological inquiry could provide further insight into OPD research. More research is also needed in order to further test and validate the theoretical model introduced in this study. The model is based on a well-documented adherence to the pedagogical principles of authentic e-learning. The hypothesis that thus follows is that the theoretical model will work in other OPD contexts using the authentic e-learning design. Testing this hypothesis with other authentic e-learning based OPD offerings is the next step in validating the theoretical model.

\section{References}

Alsofyani, M.M., Bin Aris, B., Eynon, R., \& Norazman, A. M. (2012). A preliminary evaluation of short blended online training workshop for TPACK development using technology acceptance model. Turkish Online Journal of Educational Technology, 11(3).

Amiel, T., \& Herrington, J. (2012). Authentic tasks online: Two experiences. In A. Olofsson, \& J. Lindberg (Eds.), Informed design of educational technologies in higher education: Enhanced learning and teaching (pp. 152-165). Hershey, PA: IGI Global.

Baran, B., \& Cagiltay, K. (2006). Teachers' experiences in online professional development environment. Turkish Online Journal of Educational Technology 7(14), 110-122.

Bozalek, V., Gachago, D., Alexander, L., Watters, K., Wood, D., Ivala, E., \& Herrington, J. (2013). The use of emerging technologies for authentic learning: A South African study in higher education. British Journal of Educational Technology, 44, 629-638.

Carey, R., Kleiman, G., Russell, M., \& Venable, J.D. (2009). Face-to-face and online professional development for mathematics teachers: a comparative study. Journal of Asynchronous Learning Networks 13(2), 71-87.

Collis, C., Foth, M., \& Schroeter, R. (2009). The Brisbane media map: Participatory design and authentic learning to link students and industry. Learning Inquiry, 3(3), 143-155. 
Corbin, J. \& Strauss, A. (1990). Grounded theory research: Procedures, canons and evaluative criteria. Qualitative Sociology, 13(1), 3-21.

Corno, L., \& Kanfer, R. (1993). The role of volition in learning and performance. Review of Research in Education, 19, 301-341.

Ching, C.C., \& Hursh, A. W. (2014). Peer modelling and innovation adoption among teachers in online professional development. Computers \& Education 73(1), 72-82.

Dede, C., Ketelhut, D. J., Whitehouse, P., Breit, L., \& McCloskey, E. M. (2009). A research agenda for online teacher professional development. Journal of Teacher Education, 6o, 8-19.

Garcia, L.M., \& Roblin, N.P. (2007). Innovation, research and professional development in higher education: learning from our own experience. Teaching and Teacher Education, 24(1), 104116.

Herrington, J., \& Oliver, R. (2000). An instructional design framework for authentic learning environments. Educational Technology Research and Development, 48(3), 23-48.

Herrington, J., Reeves, T.C., \& Oliver, R. (2010). A guide to authentic e-learning. London: Routledge.

Knapp, M. S. (2003). Professional development as a policy pathway. In R. E. Floden (Ed.), Review of research in education (pp. 109-158). Washington DC: American Educational Research Association.

Knowles, M. (1990). The adult learner: A neglected species (4th ed.). Houston: Gulf Publishing.

Kyalo, I.W. \& Hopkins, S. (2013). Exploring the acceptability of online learning for continuous professional development at Kenya medical training colleges. Electronic Journal of eLearning. 11(2), 82-90.

Lahti, M., Kontio, R., Pitkänen, R., \& Välimäki, M. (2014). Knowledge transfer from an e-learning course to clinical practice. Nurse Education Today 34, 842-847.

Lave, J., \& Wenger, E. (1991). Situated Learning: Legitimate Peripheral Participation. Cambridge: Cambridge University Press.

Lawless, K.A. \& Pellegrino, J.W. (2007). Professional development in integrating technology into teaching and learning: knowns, unknowns, and ways to pursue better questions and answers. Review of Educational Research, 77(4), 575-614.

Ling, L.M. \& MacKenzie, N. (2001). The professional development of teachers in Australia. European Journal of Teacher Education, 24(2), 87-98.

Liu, K.Y. (2012). A design framework for online teacher professional development. Asia Pacific Education Review, 13(4), 701-711. 
Löfström, E., \& Nevgi, A. (2007). University teaching staff as learners of the pedagogical use of ICT. International Journal of Media, Technology and Lifelong Learning, 3(1). Retrieved from http://seminar.net/index.php/volume-3-issue-1-2007-previousissuesmeny-115/77university-teaching-staff-as-learners-of-the-pedagogical-use-of-ict.

Machles, D. (2003). Situated learning: New approach to SH\&E training focuses on learning. Professional Safety, 48(9), 22-28.

McConnell, L.C., \& Monroe, M.C. (2012). Making online professional development work for Florida Project Learning Tree. Applied Environmental Education and Communication, 11(3-4), 148156.

Moghaddam, A. (2006). Coding issues in grounded theory. Issues in Educational Research, 16(1), 4758.

Phillips, R., McNaught, C., \& Kennedy, G. (2012). Evaluating e-learning: Guiding research and practice. New York \& London: Routledge.

Ozverir, I., Herrington, J., \& Osam, U. V. (2016). Design principles for authentic learning of English as a foreign language. British Journal of Education Technology, 47, 484-493.

Parker, J., Maor, D., \& Herrington, J. (2013). Authentic online learning: Aligning learner needs, pedagogy and technology. Issues in Educational Research, (23)2, 227-241.

Pintrich, P.R. (1999). The role of motivation in promoting and sustaining self-regulated learning. International Journal of Educational Research, 31, 459-470

Prosser, M., \& Trigwell, K. (1999). Understanding learning and teaching: The experience in higher education. Philadelphia: The Society for Research into Higher Education \& Open University Press.

Pu, Y.H., Wu, T.T., Chiu, P.S., \& Huang, Y.M. (2016). The design and implementation of authentic learning with mobile technology in vocational nursing practice course. British Journal of Education Technology, 47, 494-509

Reeves, T. C. (2006). Design research from a technology perspective. In J. van den Akker, K. Gravemeijer, S. McKenney, \& N. Nieveen (Eds.), Educational design research. London: Routledge.

Ruohotie, P. (2002). Oppiminen ja ammatillinen kasvu [Learning and professional growth]. Juva: WS Bookwell Oy.

Schön, D. (1983). The reflective practitioner: How professionals think in action. Basic Books: New York.

Strauss, A., \& Corbin, J. (1998). Basics of qualitative research: Techniques and procedures for developing grounded theory. Thousand Oaks, London \& New Delhi: SAGE Publications. 
Teräs, H. (2013). Dealing with "learning culture shock" in multicultural authentic e-learning. In T.

Bastiaens \& G. Marks (Eds.), Proceedings of World Conference on E-Learning in Corporate, Government, Healthcare, and Higher Education 2013, 2988-2996. Chesapeake, VA: AACE.

Valtonen, T., Kukkonen, J., Kontkanen, S., Sormunen, K., Dillon, P., \& Sointu, E. (2015). The impact of authentic learning experiences with ICT on pre-service teachers' intentions to use ICT for teaching and learning. Computers and Education, 81, 49-58.

Vermunt, J.D., \& Endedijk, M.D. (2011). Patterns in teacher learning in different phases of the professional career. Learning and Individual Differences, 21(3), 294-302.

Vu, P., Vien C., Vu, L., \& Cepero. J. (2014). Factors driving learner success in online professional development. International Review of Research in Open and Distance Learning, 15(3).

Webster-Wright, A. (2010). Authentic professional learning: Making a difference through learning at work. Dortrech: Springer.

Wenger, E., McDermott, R., \& Snyder, W.M. (2002). Cultivating communities of practice. Boston: Harvard Business School Publishing.

\section{Athabasca}

University

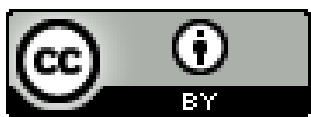

